\title{
A study of the effect of a homoeologous pairing promoter on chromosome pairing in wheat/rye hybrids using genomic in situ hybridization
}

\author{
I. P. KING, S. M. READER, K. A. PURDIE, S. E. ORFORD \& T. E. MILLER* \\ Cambridge Laboratory, Jl Centre, Colney Lane, Norwich NR4 7UJ, U.K.
}

\begin{abstract}
Genomic in situ hybridization was used to study the relative frequency of wheat/wheat and wheat/ rye homoeologous chiasma formation in Triticum aestivum cv. Chinese Spring tetrasomic for chromosome 3B $\times$ Secale cereale cv. Petkus Spring hybrids. In addition to wheat/wheat and wheat/ rye homoeologous chiasma formation, pairing between apparently non-homologous rye chromosomes was also observed. The implications of the results obtained for the introgression of rye chromatin into wheat is discussed.
\end{abstract}

Keywords: genomic in situ hybridization, homoeologous recombination, Secale cereale, Triticum aestivum.

\section{Introduction}

Wheat, which belongs to the tribe Triticeae, can be sexually hybridized with many of its wild and cultivated relatives. Such hybrids provide a bridge by which the gene pool of wheat can be increased; however, although the genomes of wheat and alien species such as rye are related, chiasma formation between wheat/ wheat and wheat/alien homoeologous chromosomes in $F_{1}$ hybrids rarely occurs (Riley et al., 1959), e.g. the frequency of bivalent formation in normal wheat/rye hybrids has been shown to be as low as 0.55 bivalent per pollen mother cell. This is the result of pairing control genes, located on wheat chromosomes, which suppress recombination between homoeologous chromosomes (for review see Gale \& Miller 1987). The strongest of these genes, $P h 1$, is located on the long arm of chromosome 5B (Okamoto, 1957; Riley \& Chapman, 1958). In plants which lack $P h 1$, homoeologous recombination between wheat and alien chromosomes can occur (Koebner \& Shepherd, 1985; King et al., 1993).

In addition to suppressors of homoeologous recombination several chromosomes of wheat, e.g. chromosome 3B (Miller et al., 1983), have been shown to carry genes which promote homoeologous recombination in wheat/rye hybrids when present in increased dosage

${ }^{*}$ Correspondence.
(Hutchinson et al., 1983; Miller et al., 1983; Miller \& Reader, 1985).

The work in this paper describes the use of genomic in situ hybridization (GISH) to determine the relative frequencies of homoeologous chiasma formation in hybrids between T. aestivum cv. Chinese Spring tetrasomic for chromosome $3 \mathrm{~B}$ and $S$. cereale cv. Petkus. The implication of the results obtained for the introgression of rye chromatin into wheat is discussed.

\section{Materials and methods}

Triticum aestivum L. cv. Chinese Spring, tetrasomic for chromosome 3B $(2 n=6 \mathrm{x}=44$, AABBDD $)$, was hybridized with Secale cereale L. cv. Petkus Spring $(2 n=2 \mathrm{x}=14, \mathrm{RR})$. The resulting five 29 -chromosome hybrids, which contained 20 single wheat chromosomes plus a homologous pair of wheat chromosome $3 \mathrm{~B}$, and seven rye chromosomes were grown in a glasshouse with a $16 \mathrm{~h}$ photoperiod at $20^{\circ} \mathrm{C}$ and an $8 \mathrm{~h}$ dark period at $15^{\circ} \mathrm{C}$.

Anthers containing PMCs at metaphase I of meiosis were fixed in 3:1 (ethanol:glacial acetic acid). In situ hybridization using genomic rye DNA as probe (75 ng per slide) and Chinese Spring as blocking DNA $(50-60 \times$ the concentration of the rye probe) was carried out as described by King et al. (1993) and Schwarzacher et al. (1992), with the following modification. Following treatment with RNase and subse- 
quent washing in $2 \times$ SSC the slides were placed in proteinase $\mathrm{K}$ reaction buffer $(20 \mathrm{~mm}$ Tris- $\mathrm{HCl}, p \mathrm{H} 8.0$, $2 \mathrm{~mm} \mathrm{CaCl}_{2}$ ) at room temperature for $2 \times 5 \mathrm{~min}$. The slides were then transferred to a solution of $0.001 \mu \mathrm{g}$ $\mu 1^{-1}$ of proteinase $\mathrm{K}$ for $15 \mathrm{~min}$ at $37^{\circ} \mathrm{C}$ and then washed several times in proteinase $\mathrm{K}$ stop buffer $(20$ mм Tris- $\mathrm{HCl}, p \mathrm{H} 8.0,2 \mathrm{~mm} \mathrm{CaCl}$, $50 \mathrm{~mm} \mathrm{MgCl}_{2}$ ). The slides were then treated with paraformaldehyde and taken through an alcohol dehydration series as previously described.

\section{Results}

Table 1 shows the number of wheat/wheat, wheat/rye and rye/rye pairing configurations, adjusted for the presence of chromosome $3 \mathrm{~B}$ (the $3 \mathrm{~B}$ chromosome pair, which was normally observed as a ring bivalent often with more than one chiasma per arm, is not included in Table 1), observed in 144 PMCs of Chinese Spring tetrasomic $3 B($ CST3B $) \times$ Petkus Spring. In total, 239 chiasmata resulting in the formation of 198 chromosome configurations were observed. In each case no paired chromosome arms with more than one chiasma were observed. Rod bivalents were the most frequent type of configuration observed (82.33 per cent). The largest configuration observed was a pentavalent involving five wheat chromosomes.

Of the 239 chiasmata scored, 168 (70.29 per cent) occurred between wheat chromosomes, the majority of which were presumably between $\mathrm{A}, \mathrm{B}$ and $\mathrm{D}$ genome homoeologues, 56 (23.43 per cent) between wheat chromosomes and the $\mathrm{R}$ genome chromosomes of $S$. cereale (Fig. 1a-f) and 15 (6.28 per cent) were between $\mathrm{R}$ genome chromosomes (Fig. 1g). The $15 \mathrm{R} / \mathrm{R}$ rod bivalents must be the result of non-homologous chromosome pairing. In each of the 56 pairing configurations observed between wheat and rye chromosomes, chiasma formation was seldom observed to occur within the telomeric heterochromatic regions of the rye chromosomes. In one case a PMC at anaphase was found to contain a wheat/rye bridge (Fig. 1h). Although a wheat/rye fragment was not observed this bridge was presumably the result of a U-type exchange between a wheat and a rye chromosome.

In total, chiasma formation between wheat and rye chromosomes was observed in 51 of 144 (35.42 per cent) of the PMCs examined.

\section{Discussion}

Using GISH it was possible to determine that the relative frequencies of wheat/wheat, wheat/rye and rye/rye chiasma formation were $70.29,23.43$ and 6.28 per cent, respectively. The relative frequency of wheat/rye chiasma formation was unexpectedly high accounting for almost a quarter of the configurations observed. An earlier study found that the relative frequency of wheat/rye chiasma formation in CST3B $\times$ Petkus Spring $\mathrm{F}_{1}$ hybrids was 4.76 per cent (Hutchinson et al., 1983). However, Miller et al. (1983) demonstrated that there is considerable variation in the frequency of pairing in such hybrids. Thus the reason for the low relative frequency of wheat/rye pairing in the previous work could have been due to sampling error as the relative frequencies of chiasma formation were determined from only eight PMCs compared with 144 PMCs in the present study.

Considerable interest has been shown in the introduction of agronomically useful genes from alien species into wheat (see Gale \& Miller, 1987 for review). The relative frequency of chiasma formation between wheat and alien chromosomes is important as it gives an indication of the ease or difficulty with which a chromatin segment from an alien species can be introgressed to wheat (Naranjo et al., 1989). In this work wheat/rye chiasma formation was shown to occur in 35.42 per cent of the PMCs examined demonstrating that $\mathrm{CST} 3 \mathrm{~B} \times$ Petkus $\mathrm{F}_{1}$ hybrids could provide a powerful means by which genes could be transferred from rye to wheat.

Fifteen rye/rye rod bivalents were observed in 15 different PMCs. Similar pairing has previously been observed between non-homologous rye chromosomes in wheat $\times$ rye hybrids (Hutchinson et al., 1983) and

Table 1 Number of wheat/wheat $(W / W)$, wheat/rye $(W / R)$ and rye/rye $(R / R)$ chromosome pairing configurations

\begin{tabular}{|c|c|c|c|c|c|c|c|c|c|c|}
\hline \multicolumn{5}{|l|}{$\mathrm{W} / \mathrm{W}$} & \multicolumn{5}{|l|}{$\mathrm{W} / \mathrm{R}$} & \multirow{2}{*}{$\begin{array}{l}\mathrm{R} / \mathrm{R} \\
\text { Rod } \\
\text { bivalent }\end{array}$} \\
\hline $\begin{array}{l}\text { Rod } \\
\text { bivalent }\end{array}$ & $\begin{array}{l}\text { Ring } \\
\text { bivalent }\end{array}$ & Trivalent & $\begin{array}{l}\text { Chain } \\
\text { quadrivalent }\end{array}$ & $\begin{array}{l}\text { Chain } \\
\text { pentivalent }\end{array}$ & $\begin{array}{l}\text { Rod } \\
\text { bivalent }\end{array}$ & $\begin{array}{l}\mathrm{W} / \mathrm{W} / \mathrm{R} \\
\text { trivalent }\end{array}$ & $\begin{array}{l}\mathrm{W} / \mathrm{R} / \mathrm{W} \\
\text { trivalent }\end{array}$ & $\begin{array}{l}\mathrm{R} / \mathrm{W} / \mathrm{R} \\
\text { trivalent }\end{array}$ & $\begin{array}{l}\mathrm{W} / \mathrm{W} / \mathrm{R} / \mathrm{W} \\
\text { quadrivalent }\end{array}$ & \\
\hline $\begin{array}{c}117 \\
(0-4)\end{array}$ & $\begin{array}{c}4 \\
(0-3)\end{array}$ & $\begin{array}{c}10 \\
(0-1)\end{array}$ & $\begin{array}{c}1 \\
(0-1)\end{array}$ & $\begin{array}{c}1 \\
(0-1)\end{array}$ & $\begin{array}{c}31 \\
(0-3)\end{array}$ & $\begin{array}{c}13 \\
(0-2)\end{array}$ & $\begin{array}{c}2 \\
(0-1)\end{array}$ & $\begin{array}{c}1 \\
(0-1)\end{array}$ & $\begin{array}{c}3 \\
(0-1)\end{array}$ & $\begin{array}{c}15 \\
(0-1)\end{array}$ \\
\hline
\end{tabular}

Numbers in parentheses indicate ranges. 


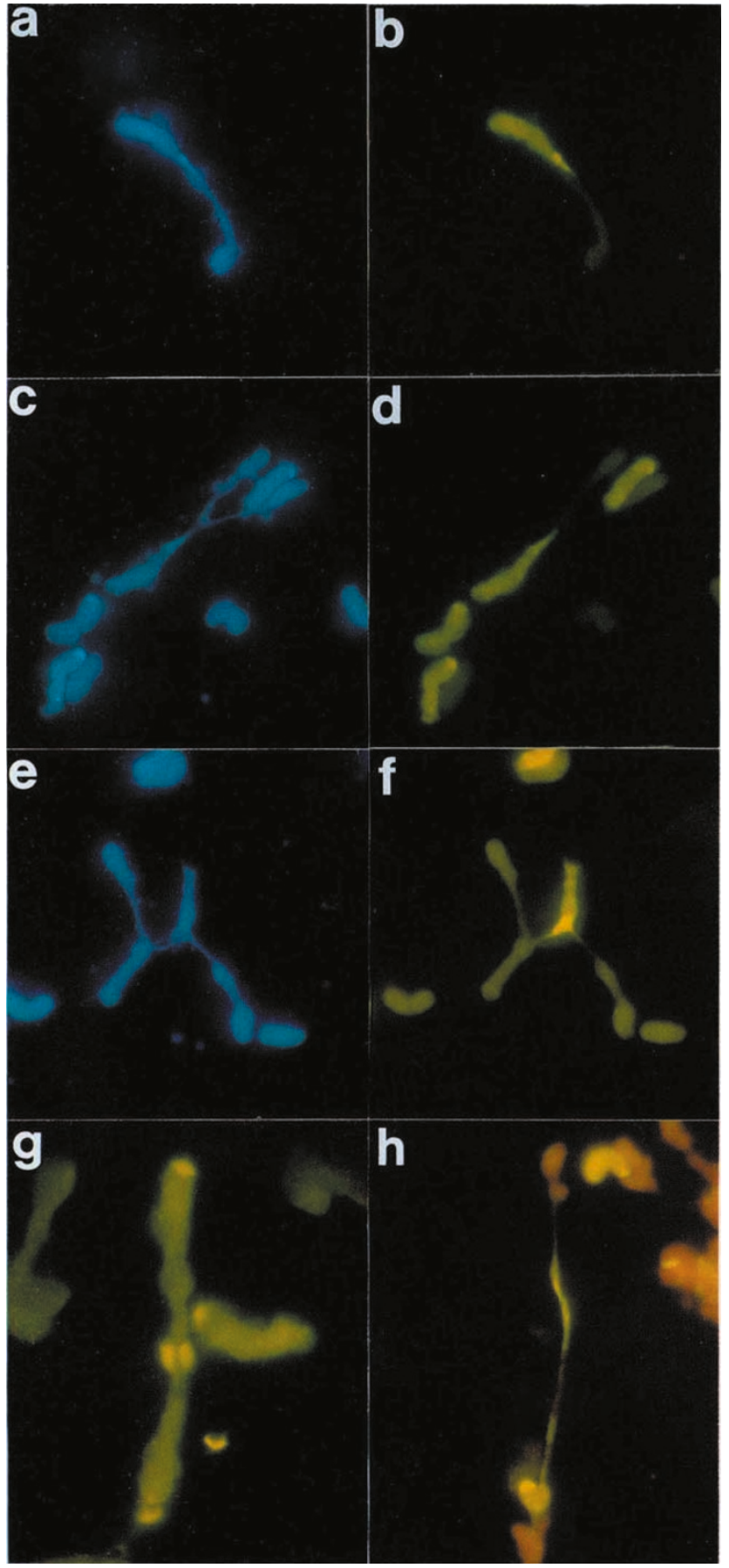

Fig. 1 PMCs showing (a) DAPI and (b) FITC images of a wheat/rye (bright green/yellow) bivalent; (c) DAPI and (d) FITC images of a wheat/rye/wheat Y shaped trivalent; (e) DAPI and (f) FITC images of a wheat/wheat/rye/wheat quadrivalent; $(\mathrm{g})$ a rye/rye bivalent; (h) a wheat/rye bridge.

between non-homologous Thinopyrum bessarabicum chromosomes in wheat $\times T h$. bessarabicum hybrids (King et al., 1993). Using GISH it was not possible to determine to which genome each wheat chromosome belonged. Thus it was not possible to determine whether non-homologous wheat/wheat recombination was also occurring. The presence of wheat/wheat associations involving more than three chromosomes may indicate non-homoeologous chiasma formation; however, as wheat contains reciprocal non-homoeologous translocations (Liu et al., 1992) the wheat quadrivalent and the pentavalent observed could be the result of homoeologous recombination of more than one homoeologous group linked by a translocation.

In this work GISH has proved to be a valuble tool for studying the effect of the homoeologous pairing promoter on chromosome $3 \mathrm{~B}$ in CST3B $\times$ Petkus $\mathrm{F}_{1}$ hybrids. Further studies using GISH are presently being carried out to determine the effect of other promoters and inhibitors of homoeologous recombination in wheat/rye hybrids.

\section{Acknowledgements}

Ian P. King, Karen Purdie and Simon Orford thank the Overseas Development Administration for financial support.

\section{References}

GALE, M. D. AND MILLER, T. E. 1987. The introduction of alien genetic variation in wheat. In: Lupton, F. G. H. (ed.) Wheat Breeding: its Scientific Basis, pp. 173-210. Chapman and Hall, London.

HUTCHINSON, J., MILLER, T. E. AND READER, S. M. 1983. C-banding at meiosis as a means of assessing chromosome affinities in the Triticeae. Can. J. Genet. Cytol., 25, 319-323.

KING, I. P., PURDIE, K. A., ORFORD, S. E., READER, S. M. AND MILLER, T. E. 1993. Detection of homoeologous chiasma formation in Triticum durum $\times$ Thinopyrum bessarabicum hybrids using genomic in situ hybridization. Heredity, 71, 369-372.

KOEBNER, R. M. D. AND SHEPHERD, K. W. 1985. Induction of recombination between rye $1 \mathrm{RL}$ and wheat chromosomes. Theor. Appl. Genet., 71, 208-215.

LIU, C. J., ATKINSON, M. D., CHINOY, C. N., DEVOS, K. M. AND GALE, M. D. 1992. Non-homologous translocations between group 4, 5 and 7 chromosomes within wheat and rye. Theor. Appl. Genet., 83, 305-312.

MILLER, T. E. AND READER, s. M. 1985. The effect of increased dosage of wheat chromosomes on chromosome pairing and an analysis of the chiasma frequencies of individual wheat bivalents. Can. J. Genet. Cytol., 27, 421-425.

MILLER, T. E., READER, S. M. AND GALE, M. D. 1983. The effect of homoeologous group 3 chromosomes on pairing and crossability in Triticum aestivum. Can. J. Genet., 25, 634-641.

NARANJo, T., FERNANDEZ-RUEDA, P., GOICOECHEA, P. G., ROCA, A. AND GIRALDEZ, R, 1989. Homoeologous pairing and recombination between the long arms of group 1 chromosomes in wheat $\times$ rye hybrids. Genome, 32, 293-301. 
OKAMOTO, M. 1957. Asynaptic effect of chromosome V. Wheat Inf. Serv., 5, 6.

RILEY, R. AND CHAPMAN, v. 1958. Genetic control of the cytologically diploid behaviour of hexaploid wheat. Nature, 182, 713-715.

RILEY, R., CHAPMAN, V. AND KIMBER, G. 1959. Genetic control of chromosome pairing in intergeneric hybrids with wheat. Nature, 183, 1244-1246.
SCHWARZACHER, T., ANAMTHAWAT-JONSSON, K., HARRISON, G. E., ISLAM, A. K. M. R., JIA, J. Z., KING, I. P., LEITCH, A. R., MILLER, T. E., READER, S. M., ROGERS, W. J., SHI, M. AND HESLOP-HARRISON, J. S. 1992. Genomic in situ hybridization to identify alien chromosome segments in wheat. Theor. Appl. Genet., 84, 778-786.

\section{Erratum}

KING, I. P., PURDIE, K. A., ORFORD, S. E., READER, S. M. AND MILLER T. E. (1993). Detection of homoeologous chiasma formation in Triticum durum $\times$ Thinopyrum bessarabicum hybrids using genomic in situ hybridization. Heredity, 71 , 369-372.

Figure 1 on page 371 was mistakenly reproduced in black-and-white and not in colour, as had been requested by the authors. The Publishers would like to apologize for this and repeat the figure in its correct form here.

Fig. 1 PMCs showing (a) two wheat bivalents (open triangles), (b) a wheat/ Th. bessarabicum bivalent (closed triangle) and a wheat/wheat bivalent (open triangles) and (c) a single $T h$. bessarabicum/Th. bessarabicum bivalent (closed triangles).
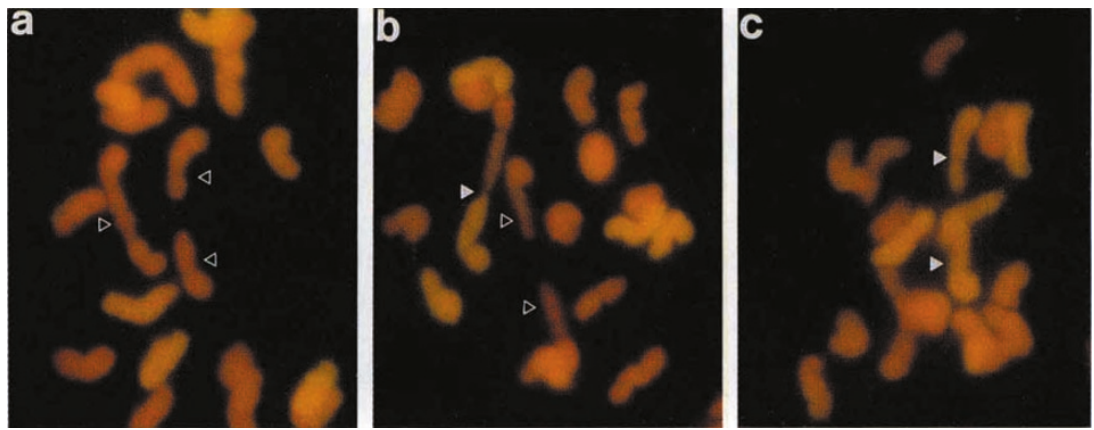